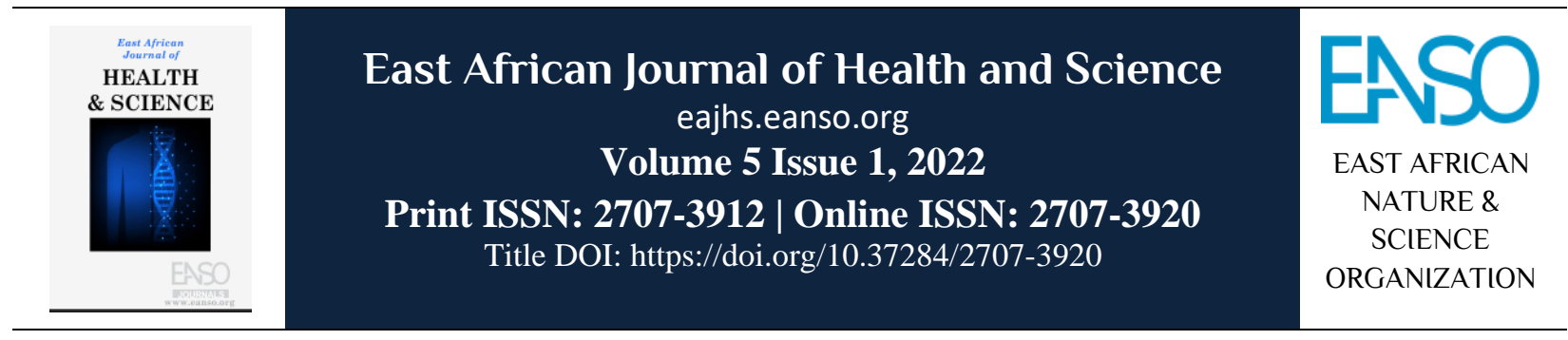

Original Article

\title{
Assessment of Women's Experience of Care during Childbirth for Quality Improvement at Level 5 Health Facilities in Bungoma County, Kenya.
}

\author{
Lucy Natecho Namusonge, RN/MPH ${ }^{1}$, Dr. Maximilla N. Wanzala, PhD ${ }^{2}$ \& Prof. Edwin K. \\ Wamukoya, $P h D^{2}$ \\ ${ }^{1}$ Kibabii University, P. O. Box 2008-50200, Bungoma, Kenya. \\ ${ }^{2}$ Masinde Muliro University of Science and Technology, P. O. Box 190-50100, Kakamega, Kenya. \\ *Author for correspondence ORCID ID: https://orcid.org/0000-0001-8319-7467; email: lucy.namusonge@gmail.com.
}

Article DOI: https://doi.org/10.37284/eajhs.5.1.521

\section{Date Published: ABSTRACT}

05 January 2022 High maternal and newborn mortality is a pressing problem in developing countries. Poor treatment during childbirth contributes directly and

Keywords: indirectly to this problem. Many women experience disrespectful and abusive treatment during childbirth worldwide which violates their rights.

Level 5 Health Facility, In Kenya, $20 \%$ of women report having experienced some form of

Maternity Care,

Perception,

Quality of care,

Respectful Maternity

Care,

Disrespect,

Abuse. disrespect and abuse (D\&A). Bungoma County is among the 15 counties with the worst maternal and newborn health statistics in Kenya. The maternal mortality rate is 382 per 100,000 live births and newborn deaths 32 per 1,000 live births, while skilled birth attendance is $41.4 \%$. This study was motivated by the poor maternal and newborn indicators, rising incidences of D\&A, limited formal research on respectful maternity care. The study aimed at assessing women's experience of care during childbirth at Level 5 health facilities in Bungoma County. The specific objectives were to determine the women's experiences of care during childbirth, to determine factors contributing to disrespect and abuse during childbirth and to identify strategies for addressing issues affecting respectful maternity care for promoting quality of maternal and newborn care. A cross-sectional descriptive study design was used. It involved 360 mothers. Analysis of quantitative data was done using SPSS. Descriptive statistics were presented in graphs, tables, frequencies and percentages. Qualitative data was analysed thematically. The prevalence of D\&A was $42.2 \%$, younger age and lower education aggravated D\&A. Autonomy, privacy and confidentiality, and absence of birth companionship were major aspects of D\&A. Health workforce shortage, inadequate supervision, space and beds,

1 | This work is licensed under a Creative Commons Attribution 4.0 International License. 
poor provider-patient relationships were factors leading to D\&A. It was concluded that there is a need for increased incorporation of Respectful Maternity Care (RMC) in routine care, deploy more staff, avail equipment and supplies, and enhance support supervision. The study information intends to assist stakeholders in prioritising policy actions for improving the quality of maternal and newborn health outcomes and indicators.

\section{APA CITATION}

Namusonge, L. N., Wanzala, M. N. \& Wamukoya, E. K. (2022). Assessment of Women's Experience of Care during Childbirth for Quality Improvement at Level 5 Health Facilities in Bungoma County, Kenya. East African Journal of Health and Science, 5(1), 1-18. https://doi.org/10.37284/eajhs.5.1.521.

\section{CHICAGO CITATION}

Namusonge, Lucy Natecho, Maximilla N. Wanzala, \& Edwin K. Wamukoya. 2022. "Assessment of Women's Experience of Care during Childbirth for Quality Improvement at Level 5 Health Facilities in Bungoma County, Kenya.”. East African Journal of Health and Science 5 (1), 1-18. https://doi.org/10.37284/eajhs.5.1.521.

\section{HARVARD CITATION}

Namusonge, L. N., Wanzala, M. N. \& Wamukoya, E. K. (2022) “Assessment of Women's Experience of Care during Childbirth for Quality Improvement at Level 5 Health Facilities in Bungoma County, Kenya.”, East African Journal of Health and Science, 5(1), pp. 1-18. doi: 10.37284/eajhs.5.1.521.

\section{IEEE CITATION}

L. N. Namusonge, M. N. Wanzala, \& E. K. Wamukoya, “Assessment of Women's Experience of Care during Childbirth for Quality Improvement at Level 5 Health Facilities in Bungoma County, Kenya.”, EAJHS, vol. 5, no. 1, pp. 1-18, Jan. 2022.

\section{MLA CITATION}

Namusonge, Lucy Natecho, Maximilla N. Wanzala, \& Edwin K. Wamukoya. “Assessment of Women's Experience of Care during Childbirth for Quality Improvement at Level 5 Health Facilities in Bungoma County, Kenya.”. East African Journal of Health and Science, Vol. 5, no. 1, Jan. 2022, pp. 1-18, doi:10.37284/eajhs.5.1.521.

\section{INTRODUCTION}

High maternal and newborn mortality and morbidity remains a pressing problem in developing countries (Furuta et al., 2014). Maternity care interventions are related to pregnancy, childbirth, and the postpartum period aimed at improving maternal and newborn health outcomes. They include monitoring the health and wellbeing of the mother and baby, health education, and assistance during childbirth. Its components entail Respectful Maternity Care (RMC); Emergency Obstetric and Newborn Care (EmONC); Essential Newborn Care (ENC); Focused Antenatal Care (FANC); and Malaria in Pregnancy (MIP) (Wiegers, 2009). The quality aspects to be put into consideration in order to have an impactful outcome on quality include evidencebased practices for routine care and management of complications; training of healthcare providers; monitoring and evaluation; actionable information systems; effective communication; emotional support; respect and preservation of dignity; competent and motivated personnel; availability of essential physical resources. This study focused on Respectful Maternity care in promoting quality as a component of maternity care. Respectful Maternity Care is not only a crucial component of quality of care, it is a human right (WHO, 2018).

Treatment refers to care during childbirth that is respectful and responsive to individual women and their families' preferences, needs, and values. It emphasises the quality of patient experience (Afulani et al., 2017). Poor treatment which entails physical abuse, sexual abuse, verbal abuse, stigma and discrimination, failure to meet professional standards of care, the poor rapport between women and providers and health systems conditions and constraints during childbirth contribute both directly and indirectly to maternal and newborn morbidity and mortality. The evidence based on safety, its root causes and contributing factors, as well as the cost-effective solutions to common problems are limited. Due to this fact, research on maternal and neonatal care has been acknowledged by the World Health Organization (WHO) Patient 
Safety Programme as one of the top 20 global research priorities in low-income countries whose economies are in transition (WHO, 2010).

Many women and their babies die as a result of poor care, even after reaching a health facility (Bohren $e t$ $a l ., 2014)$. Accessing labour and childbirth care in health care facilities may not guarantee good quality care. Disrespectful and undignified care is prevalent in many facility settings globally, particularly for underprivileged populations, and this not only violates their human rights but is also a significant barrier to accessing intrapartum care services (Borhen et al., 2015). According to WHO, every woman has the right to the highest attainable standard of health, which includes the right to dignified, respectful healthcare (WHO, 2014a).

In Kenya, maternal and newborn mortality rates are unacceptably high at 400 maternal deaths per 100,000 live births and a neonatal mortality rate of 22 per 1000 live births, respectively (WHO, 2014b). While this is below the Sub-Saharan average of 640 maternal deaths per 100,000 and 27 neonatal deaths per 1000 live births, Kenya experiences slow progression in maternal and neonatal health (KDHS, 2014). Bungoma County is ranked $6^{\text {th }}$ amongst fifteen Counties with the highest number of poor reproductive, maternal and neonatal health statistics in Kenya which contributes over $60 \%$ of the national level (KNBS/ICF Macro, 2015). At this level of magnitude, improvements in maternal survival by 2030 present a key challenge.

Currently, Respectful Maternity Care is a top priority in the World Health Organization (WHO) recommendations on intrapartum care or a positive childbirth experience. The WHO recommends the provision of respectful maternity care in accordance with the human rights-based approach to decrease maternal and newborn morbidity and mortality and improve women's experience of labour and childbirth and address health disparities (WHO, 2018). WHO identified RMC as a key component of quality care in the WHO Quality of MNH Care Framework. RMC continues to gain prominence around the world.

Undertaking this study helped determine the experience of women during childbirth as well as the prevalence of disrespect and abuse in Bungoma County hence forming a basis for informing policy on issues that need to be addressed so as to improve the quality of care. The study will also help in advocacy that will catalyse a movement to protect the safety and dignity of women during childbirth and ensure RMC is integrated into the broader quality of care movement that may impact positively on the outcomes of maternal and neonatal health hence contributing immensely towards the SDG's vision and the Big 4 Agenda 3 which is Universal Health Coverage (UHC).

\section{Objective of the Study}

The broad objective of the study was to assess women's experience of care during childbirth at Level 5 health facilities in Bungoma County. The specific objectives were to:

- Determine women's experience of care during childbirth at Level 5 health facilities in Bungoma County

- Determine factors contributing to disrespect and abuse during childbirth at Level 5 health facilities in Bungoma County

- Identify strategies for addressing issues affecting respectful maternity care for promoting quality of maternal and newborn care

\section{MATERIALS AND METHODS}

\section{Research Design}

The study employed a cross-sectional descriptive study design involving randomisation. It utilised quantitative and qualitative approaches.

\section{Study Area}

The study was conducted in maternity units of Level 5 health facilities in Bungoma County, namely Bungoma County Referral Hospital and Webuye County Hospital

\section{Target Population}

The target population comprised of postnatal mothers who had delivered three days preceding the study at Bungoma County Referral Hospital and Webuye County Hospital, respectively and Key informants. Focus group discussions were also

3 | This work is licensed under a Creative Commons Attribution 4.0 International License. 
administered to selected postnatal mothers for triangulation.

\section{Sample Size Determination}

The target population size for postnatal mothers was estimated to be less than 10,000; thus, the formula below was used to determine the sample size (Fisher et al., 1991; cited in Kothari (2004).

$n=\frac{z^{2} p q}{d^{2}}$

Where $n=$ the desired sample size; $\mathrm{z}=$ the standard normal deviate, which corresponds to $95 \%$ confidence level (1.96); $\mathrm{p}=$ the proportion in the target population estimated to have the particular characteristic being studied. In this study, $p$ was the proportion of women who had delivered in health facilities which was estimated at $41.4 \%$. Hence $p$ was $0.414 ; \mathrm{q}=1.0-\mathrm{p} ; \mathrm{d}=$ degree of accuracy desired, usually set at 0.05 .

$n=\frac{1.96^{2} * 0.414 * 0.586}{0.05^{2}}=367$. Hence the sample size was 367 .

Adjusting for a smaller sample size and reducing the sampling error margin, the second formula was used as follows:

$n f=\frac{n}{\left[1+\left(\frac{n}{N}\right)\right]}$

Where $n f=$ the desired sample size (when the population is less than 10,000$) ; \mathrm{N}=$ the estimate of the target population size (4176);

$n f=\frac{367}{\left[1+\left(\frac{367}{7739}\right)\right]}=350.5$ Hence the sample size was 351 for exit interview that was finally adjusted for an anticipated non-response rate of $3 \%$ according to Gary (2007) to 360 divided equally between Bungoma County Referral Hospital (180) and Webuye County Hospital (180), respectively

\section{Data Collection Methods and Procedure}

\section{Data Collection Tools/Instruments}

Data was collected using exit interviews, focused group discussion (knowledge, practice and experience questionnaires, respectively) and key informant interviews (Oppenheim, 2009).
Questionnaires were administered by the research assistants.

\section{Data Analysis and Presentation}

Descriptive statistics were used to analyse the research data and the analysis was guided by the objectives of the study. All the quantitative data analysis was done using a statistical package for social sciences (SPSS v. 25.0). Descriptive statistics were presented in graphs, tables, frequencies and numerations. Qualitative data was analysed thematically.

\section{RESULTS}

\section{Demographic Information of the Respondents}

The mean age of respondents was $22 \pm 4.1$ years ranging from 15-49 years age group who are women of reproductive age (WRA) hence justifying the grouping of the younger women 15-19 years of age since they are usually a special group that is most vulnerable. The majority of the women were aged 20-29 years (44\%) of whom $62 \%$ experienced some form of disrespect and abuse, followed by $31.6 \%$ in the 30-39 age group of whom $49 \%$ experienced some form of disrespect and abuse. Respondents aged 15-19 years were $15.8 \%$ of whom $100 \%$ experienced some form of disrespect and abuse, while those aged $40-49$ years were $8.6 \%$ of whom $6 \%$ experienced some form of disrespect and abuse.

The majority of the women $(52.5 \%)$ were married of whom $51.8 \%$ experienced some form of disrespect and abuse, while $26.7 \%$ of the women were single of whom $42.7 \%$ experienced some form of disrespect and abuse. $20.8 \%$ of the women were divorced/separated of whom $20 \%$ experienced some form of disrespect and abuse.

The majority of the respondents had a college and above level of education (38.6\%) of whom 38.2\% experienced some form of disrespect and abuse, followed by those with postprimary/vocational/secondary level of education (37.3\%) of whom $53.7 \%$ experienced some form of disrespect and abuse. Respondents who had primary or less level of education were $24.1 \%$ of whom $71.2 \%$ experienced some form of disrespect and abuse

4 | This work is licensed under a Creative Commons Attribution 4.0 International License. 
The majority of the women were not employed (58\%) of whom $55.5 \%$ experienced some form of disrespect and abuse, followed by those who were employed (30\%) of whom $25 \%$ experienced some form of disrespect and abuse. Women who were self-employed were $12 \%$ of whom $27.9 \%$ experienced some form of disrespect and abuse.

Sixty per cent $(60 \%)$ of the respondents had 1-2 children of whom $50.9 \%$ experienced some form of disrespect and abuse, followed by those who had 35 children $(60 \%)$ of whom $50.9 \%$ experienced some form of disrespect and abuse. $10 \%$ had $>5$ children of whom $22 \%$ experienced some form of disrespect and abuse.
The majority of the women (51\%) were getting a monthly income of $<5,000$ of whom $90 \%$ experienced some form of disrespect and abuse. Those earning a monthly income between Ksh. $5000-10,000$ were at $38 \%$ of whom $84 \%$ experienced some form of disrespect and abuse and those earning a monthly income $>10,000$ were at $11 \%$ of whom $29 \%$ experienced some form of disrespect and abuse.

The majority of respondents $(99 \%)$ were from the Christian religion of whom $80 \%$ experienced some form of disrespect and abuse and $4 \%$ were Muslims at $1 \%$ of whom $25 \%$ experienced some form of disrespect and abuse (Table 1).

Table 1: Socio-Demographic Characteristics of the Respondents

\begin{tabular}{|c|c|c|c|}
\hline \multicolumn{2}{|l|}{ Independent variables } & $f(\%)$ & $\begin{array}{l}\text { Experience of any } \\
\text { form of D\&A }(\%)\end{array}$ \\
\hline \multirow[t]{5}{*}{ Age of respondents } & & Mean age $=22 \pm 4.1$ & \\
\hline & $15-19$ & $57(15.8)$ & $57(100 \%)$ \\
\hline & $20-29$ & $158(44)$ & $98(62 \%)$ \\
\hline & $30-39$ & $114(31.6)$ & $80(49 \%)$ \\
\hline & $40-49$ & $31(8.6)$ & $2(6 \%)$ \\
\hline \multirow[t]{3}{*}{ Marital Status } & Married & $189(52.5)$ & $98(51.8 \%)$ \\
\hline & Single & $96(26.7)$ & $41(42.7 \%)$ \\
\hline & Divorced/separated & $75(20.8)$ & $15(20 \%)$ \\
\hline \multirow[t]{3}{*}{ Education Level } & Primary or less & $87(24.1)$ & $62(71.2 \%)$ \\
\hline & $\begin{array}{l}\text { Post primary/Vocational/ } \\
\text { Secondary }\end{array}$ & $134(37.3)$ & $72(53.7 \%)$ \\
\hline & College and above & $9(38.6)$ & $56(40.2 \%)$ \\
\hline \multirow{3}{*}{ Occupation } & Employed & $108(30)$ & $27(25 \%)$ \\
\hline & Self-employed & $43(12)$ & $12(27.9 \%)$ \\
\hline & Not employed & $209(58)$ & $116(55.5 \%)$ \\
\hline \multirow[t]{3}{*}{ Number of Children } & - $1-2$ & $216(60)$ & $110(50.9 \%)$ \\
\hline & - $3-5$ & $108(30)$ & $42(38.8 \%)$ \\
\hline & - $>5$ & $36(10)$ & $8(22 \%)$ \\
\hline \multirow{3}{*}{$\begin{array}{l}\text { Monthly } \\
\text { (Kshs) }\end{array}$} & - $\quad<5000$ & $182(51)$ & $164(90 \%)$ \\
\hline & - $5000-10,000$ & $137(38)$ & $115(84 \%)$ \\
\hline & - $>10,000$ & $41(11)$ & $12(29 \%)$ \\
\hline \multirow[t]{3}{*}{ Religion } & Christian & $356(99)$ & $285(80 \%)$ \\
\hline & Muslim & $4(1)$ & $1(25 \%)$ \\
\hline & Others & $0(0)$ & $0(0 \%)$ \\
\hline
\end{tabular}

Treatment of Mothers during Childbirth (Experience of Care/Respectful Maternity Care)

Patient exit interview tool was used to collect information on women's experience of care and it addressed issues to do with dignity and respect; privacy, autonomy and confidentiality; communication; supportive care; facility environment and transparency of payments.

5 | This work is licensed under a Creative Commons Attribution 4.0 International License. 


\section{Dignity and Respect}

The majority of the respondents $(86.4 \%)$ said that the doctors, nurses or other healthcare providers introduced themselves to them when they first came to see them during their time in the facility, while $13.6 \%$ reported that the doctors, nurses or other healthcare providers did not introduce themselves. $89.2 \%$ reported that the doctors, nurses, or other healthcare providers called them by name, while $10.8 \%$ reported to have not been called by name. The majority of the respondents $(93.6 \%)$ reported having felt respected by the doctors, nurses, or other health staff at the facility, while $6.4 \%$ reported that they did not feel respected (see Table 2).

The majority of the respondents $(92.7 \%)$ said that the doctors, nurses, or other staff at the facility treated them in a friendly manner, while $7.3 \%$ said that they were not treated in a friendly manner. 93.6\% said that they felt cared for by the doctors, nurses or other staff at the facility, while $6.4 \%$ said that they did not feel cared for (see Table 2). The majority of the respondents $(93.6 \%)$ said that they were not shouted at, scolded, insulted, threatened or talked to rudely by the doctors, nurses, or other health providers, while $6.4 \%$ reported having been shouted at, scolded, insulted, threatened or talked to rudely (see Table 2).

$96.9 \%$ of the respondents said that they were not treated roughly like pushed, beaten, slapped, pinched, physically restrained or gagged, while $3.1 \%$ reported having been treated roughly. The majority of the respondents $(97.5 \%$ ) said that they were not forced to stay at the facility against their will or because they could not be able to pay the hospital bill, while $2.5 \%$ reported having been forced to stay at the facility against their will (see Table 2). $4.8 \%$ of the respondents experienced a high level of dignity and respect, $90.4 \%$ experienced a moderate level of dignity and respect, while $4.8 \%$ experienced a low level of dignity and respect (see Table 3). Focused Group Discussion was also carried out on postnatal mothers who had not participated in the exit interview to find out their experience on dignity and respect

"I was satisfied with the services I was offered. The doctors and nurses were very caring," said an FGD participant

"I received unfriendly and insensitive treatment when I told the nurse to allow my mother-in-law help me carry the baby since I was still in pain due to caesarean section and she scolded me, saying that she is not the one who told me to get pregnant so as to come in the hospital to disturb them," said an FGD participant.

"I was harassed because my baby's injection line came out," said an FGD participant.

Table 2: Dignity and Respect

\begin{tabular}{|c|c|c|c|}
\hline Statement & Yes & No & Total \\
\hline \multicolumn{2}{|l|}{ Did the doctors, nurses or other healthcare providers introduce themselves311 } & 49 & 360 \\
\hline to you? & $86.4 \%$ & $13.6 \%$ & $100.0 \%$ \\
\hline \multicolumn{2}{|l|}{ Did the doctors, nurses, or other healthcare providers call you by your321 } & 39 & 360 \\
\hline name? & $89.2 \%$ & $10.8 \%$ & $100.0 \%$ \\
\hline \multicolumn{2}{|l|}{ Can you say that you felt respected by the doctors, nurses, or other staff at337 } & 23 & 360 \\
\hline the facility? & $93.6 \%$ & $6.4 \%$ & $100.0 \%$ \\
\hline \multicolumn{2}{|l|}{ Can you say that the doctors, nurses, or other staff at the facility treated you332 } & 26 & 358 \\
\hline in a friendly manner? & $92.7 \%$ & $7.3 \%$ & $100.0 \%$ \\
\hline \multirow{2}{*}{ Did you feel cared for by the doctors, nurses, or other staff at the facility? } & 334 & 23 & 357 \\
\hline & $93.6 \%$ & $6.4 \%$ & $100.0 \%$ \\
\hline \multicolumn{2}{|l|}{ Were you shouted at, scolded, insulted, threatened or talked to rudely by the 23} & 336 & 359 \\
\hline doctors, nurses, or other health providers? & $6.4 \%$ & $93.6 \%$ & $100.0 \%$ \\
\hline \multicolumn{2}{|l|}{ Were you treated roughly like pushed, beaten, slapped, pinched, physically11 } & 349 & 360 \\
\hline \multirow[t]{2}{*}{ restrained or gagged? } & $3.1 \%$ & $96.9 \%$ & $100.0 \%$ \\
\hline & 9 & 351 & 360 \\
\hline
\end{tabular}

6 | This work is licensed under a Creative Commons Attribution 4.0 International License. 
East African Journal of Health and Science, Volume 5, Issue 1, 2022

Article DOI: https://doi.org/10.37284/eajhs.5.1.521

\begin{tabular}{|c|c|c|}
\hline Statement & No & Total \\
\hline $\begin{array}{l}\text { Were you forced to stay at the facility against your will because you could } 2.5 \% \\
\text { not pay your bill? }\end{array}$ & $97.5 \%$ & $100.0 \%$ \\
\hline
\end{tabular}

Table 3: Cumulative Rating of Dignity and Respect

\begin{tabular}{llll}
\hline Category & Frequency & Per cent & Cumulative Percent \\
\hline Highly & 18 & 4.8 & 4.8 \\
Moderate & 325 & 90.8 & 95.6 \\
Low & 17 & 4.4 & 100.0 \\
Total & $\mathbf{3 6 0}$ & $\mathbf{1 0 0 . 0}$ & \\
\hline
\end{tabular}

\section{Privacy, Autonomy and Confidentiality}

The majority of the respondents $(62 \%)$ reported that they did not feel like other people not involved in their care could hear their discussion while speaking to the doctors, nurses or other staff at the facility, while $38 \%$ reported that their discussion could be heard by other people not involved in their care (see Table 4).

95\% reported that while being examined in the labour room they were covered up with a cloth or blanket or screened with a curtain to ensure they did not feel exposed, while 5\% reported to have not been covered or screened with a curtain. 96\% thought that their health information was or would be kept confidential at the health facility, while $4 \%$ thought that their health information would not be kept confidential (see Table 4).

The majority of the respondents (94\%) said that the doctors, nurses or other staff did not involve them in decision making about their care, while $6 \%$ said that they involved them in decision making about their care (see Table 4). The majority of the respondents (98\%) reported that permission or consent was not obtained from them by the doctors, nurses or other staff at the facility before doing procedures and examinations on them, while $2 \%$ reported that permission or consent was obtained (see Table 4).

$98 \%$ of the respondents reported that they were not allowed to be in the position of their choice during delivery, while $2 \%$ reported having been allowed to be in the position of their choice during delivery (see Table 4). Cumulatively on the experience of privacy, autonomy and confidentiality, $3.4 \%$ rated it highly, $87.5 \%$ rated it moderately, while $9.1 \%$ rated it to be low (see Table 5).

"My information was kept confidential and the nurses were supportive, friendly and calm," said an FGD participant.

"While in labour, I was neither asked for consent during examinations nor informed on my progress of labour, " said an FGD participant

"There is no privacy due to inadequate bed capacity which forces mothers to share beds alongside their newborn babies," said a midwife.

\section{Table 4: Autonomy, Privacy and Confidentiality}

\begin{tabular}{|c|c|c|}
\hline \multirow{2}{*}{$\begin{array}{l}\text { Statement } \\
\text { While speaking to the doctors, nurses, or other staff at the facility, did you feel138 }\end{array}$} & No & Total \\
\hline & 222 & 360 \\
\hline other people not involved in your care could hear your discussion? $38 \%$ & $62 \%$ & $100 \%$ \\
\hline While being examined in the labour room, were you covered up with a cloth or341 & 19 & 360 \\
\hline blanket or screened with a curtain to secure you did not feel exposed? $\quad 95 \%$ & $5 \%$ & $100 \%$ \\
\hline \multirow{2}{*}{$\begin{array}{l}\text { Do you think your health information was or will be kept confidential at this } 344 \\
\text { facility? }\end{array}$} & 16 & 360 \\
\hline & $4 \%$ & $100 \%$ \\
\hline Did the doctors, nurses, or other staff at the facility involve in decision making22 & 338 & 360 \\
\hline \multirow{2}{*}{$\begin{array}{ll}\text { about your care } & 6 \% \\
& 9\end{array}$} & $94 \%$ & $100 \%$ \\
\hline & 351 & 360 \\
\hline
\end{tabular}

7 | This work is licensed under a Creative Commons Attribution 4.0 International License. 
East African Journal of Health and Science, Volume 5, Issue 1, 2022

Article DOI: https://doi.org/10.37284/eajhs.5.1.521

\begin{tabular}{|c|c|c|c|}
\hline Statement & Yes & No & Total \\
\hline $\begin{array}{l}\text { Was permission or consent obtained from you by the doctor's nurses or } \\
\text { and the facility before doing procedures and examination on you }\end{array}$ & $\mathrm{ff} 2 \%$ & $98 \%$ & $100 \%$ \\
\hline Were you allowed to be in the position of your choice during delivery & $\begin{array}{l}9 \\
2 \%\end{array}$ & $\begin{array}{l}351 \\
98 \%\end{array}$ & $\begin{array}{l}360 \\
100 \%\end{array}$ \\
\hline
\end{tabular}

Table 5: Cumulative Experience of Autonomy, Privacy and Confidentiality

\begin{tabular}{lllll}
\hline Category & Frequency & Per cent & Valid Percent & Cumulative Percent \\
\hline Highly & 13 & 3.4 & 3.4 & 3.4 \\
Moderate & 330 & 87.5 & 87.5 & 90.9 \\
Low & 17 & 9.1 & 9.1 & 100.0 \\
\hline Total & $\mathbf{3 6 0}$ & $\mathbf{1 0 0 . 0}$ & $\mathbf{1 0 0 . 0}$ & \\
\hline
\end{tabular}

\section{Communication}

The majority of the respondents $(98 \%)$ reported that doctors, nurses or other staff at the facility spoke to them in a language that they could understand, while $2 \%$ reported that they were not spoken to in a language they could understand. $90 \%$ of the respondents said that the doctors and nurses explained to them why they were doing examinations and procedures on them, while $10 \%$ reported that they were not explained to why examinations and procedures were being done on them (see Table 6).

$88 \%$ of the respondents reported that the doctors and nurses explained to them why they were giving them any medication, while $12 \%$ reported that they were not explained why they were being given any medication. The majority of the respondents $(88 \%)$ said that they felt that they could ask doctors, nurses and other staff at the facility any questions they had, while $12 \%$ reported that they did not feel like they could ask questions they had (see Table 6). Cumulatively $95.3 \%$ of the respondents had a positive experience when it comes to communication, while $4.7 \%$ experienced communication moderately (see Table 7).

"The nurses were very supportive; they gave me a lot of health education on baby care. It was the best experience ever," said an FGD participant.

"I can say that most of the doctors and nurses are good apart from a few who have a negative attitude," said an FGD participant.

"I was not informed which medication my baby and I were being given. I was even at one time asked which medication I was on, yet I did not have any idea," said an FGD participant.

"My baby was taken to nursery without being told the reason why. He stayed there for 24 hours without me seeing him," said an FGD participant.

"I wish I could report my dissatisfaction, but because a weak person has no right, I will just let it go," said an FGD participant.

\section{Table 6: Communication}

\begin{tabular}{lrll}
\hline Statement & Yes & No & Total \\
\hline Did the doctors, nurses, or other staff at the facility could speak to you in a language 351 & 9 & 360 \\
you would understand? & $98 \%$ & $2 \%$ & $100 \%$ \\
\hline Did the doctors and nurses explain to you why they were doing examinations or 323 & 37 & 360 \\
procedures on you? & $90 \%$ & $10 \%$ & $100 \%$ \\
\hline
\end{tabular}

8 This work is licensed under a Creative Commons Attribution 4.0 International License. 
East African Journal of Health and Science, Volume 5, Issue 1, 2022

Article DOI: https://doi.org/10.37284/eajhs.5.1.521

Table 7: Cumulative Experience in Communication

\begin{tabular}{llll}
\hline Category & Frequency & Per cent & Cumulative Percent \\
\hline Highly & 341 & 95.3 & 95.3 \\
Moderate & 19 & 4.7 & 100.0 \\
Low & 17 & 9.1 & 100.0 \\
Total & $\mathbf{3 6 0}$ & $\mathbf{1 0 0 . 0}$ & \\
\hline
\end{tabular}

\section{Supportive Care}

The majority of the respondents (93\%) said that the doctors and nurses at the facility asked them about how they were feeling, while $7 \%$ were not asked how they were feeling. $88 \%$ of the respondents said that the doctors, nurses or other staff in the facility addressed their anxiety and fears, while $12 \%$ said that their fears and anxieties were not addressed (see Table 8).

$82 \%$ of the respondents said that the doctors and nurses asked them how much pain they were in, while $18 \%$ said that they were not asked how much pain they were in. The majority of the respondents (77\%) reported that the doctors and nurses did everything they could to help control their pain, while $23 \%$ reported that their pain was not controlled (see Table 8).

The majority of the respondents $(94 \%)$ felt that the doctors, nurses or other staff at the facility paid attention, while $6 \%$ felt that they did not pay attention. $89 \%$ of the respondents said that when they felt hungry/thirsty, they were allowed to eat and drink, while $11 \%$ were not allowed to eat and drink when they felt hungry/thirsty (see Table 8). $83.6 \%$ said that they were allowed to stay with someone whom they wanted to stay with them during labour, while $16.4 \%$ said that they were not allowed. The majority of the respondents $(54.2 \%)$ said that they were not allowed to have a birth companion stay with them during delivery, while $45.8 \%$ said that they were allowed to have a birth companion during delivery (see Table 9). Cumulatively the experience of supportive care was highly rated at $90 \%$, the moderate rating was at $8.1 \%$, while the low rating was at $1.9 \%$ (see Table 9).

"This was my first time to deliver and I felt very much supported by the nurses. God bless them," said an FDG participant.

\section{Table 8: Supportive Care}

\begin{tabular}{|c|c|c|c|}
\hline Statement & Yes & No & Total \\
\hline \multirow{2}{*}{ Did the doctors and nurses at the facility talk to you about how you were feeling? } & 334 & 26 & 360 \\
\hline & $93 \%$ & $7 \%$ & $100 \%$ \\
\hline \multirow{2}{*}{ Did the doctors, nurses, or other staff in the facility support your anxiety and fears? } & 317 & 43 & 360 \\
\hline & $88 \%$ & $12 \%$ & $100 \%$ \\
\hline \multirow{2}{*}{ Did the doctors and nurses ask how much pain you were in? } & 294 & 66 & 360 \\
\hline & $82 \%$ & $18 \%$ & $100 \%$ \\
\hline \multirow{2}{*}{ Do you feel the doctors or nurses did everything they could to help control your pain } & 277 & 83 & 360 \\
\hline & $77 \%$ & $23 \%$ & $100 \%$ \\
\hline \multicolumn{2}{|l|}{ When you needed help did you feel the doctors, nurses or other staff at the facility paid339 } & 21 & 360 \\
\hline attention? & $94 \%$ & $6 \%$ & $100 \%$ \\
\hline \multirow{2}{*}{ Did the doctors and nurses pay attention to you during your stay at the facility? } & 340 & 20 & 360 \\
\hline & $\overline{94 \%}$ & $6 \%$ & $100 \%$ \\
\hline \multirow{2}{*}{ When you felt hungry/thirsty, were you allowed to eat or drink? } & 320 & 39 & 359 \\
\hline & $89 \%$ & $11 \%$ & $100 \%$ \\
\hline
\end{tabular}

9 | This work is licensed under a Creative Commons Attribution 4.0 International License. 
East African Journal of Health and Science, Volume 5, Issue 1, 2022

Article DOI: https://doi.org/10.37284/eajhs.5.1.521

Table 9: Presence of a Birth Companion During Labour, Delivery and Supportive Care

\begin{tabular}{llll}
\hline Category & Frequency & Per cent & Cumulative Percent \\
\hline During Labour & & & \\
\hline Highly & 301 & 83.6 & 83.6 \\
Moderate & 59 & 16.4 & 100.0 \\
Low & 17 & 9.1 & 100.0 \\
Total & $\mathbf{3 6 0}$ & $\mathbf{1 0 0 . 0}$ & \\
\hline During Delivery & & \\
\hline Highly & 165 & 45.8 & 45.8 \\
Moderate & 195 & 54.2 & 100.0 \\
Low & 17 & 9.1 & 100.0 \\
Total & $\mathbf{3 6 0}$ & $\mathbf{1 0 0 . 0}$ & \\
\hline Experience of Supportive Care & & \\
\hline Highly & 323 & 90.0 & 90.0 \\
Moderate & 29 & 8.1 & 98.1 \\
Low & 8 & 1.9 & 100.0 \\
Total & $\mathbf{3 6 0}$ & $\mathbf{1 0 0 . 0}$ & \\
\hline
\end{tabular}

\section{Facility Environment}

The majority of the respondents (90\%) said that there were enough staff in the facility to care for them, while $10 \%$ said that there were no enough staff. 54\% reported that the labour and postnatal wards at the facilities were crowded, while $46 \%$ said that they were not crowded. $99 \%$ said water was available in the facility, while $1 \%$ said that water was not available. $100 \%$ said that electricity was available in the facility. Overally, $98 \%$ said that they felt safe in the facility, while $2 \%$ said that they did not feel safe (see Table 10). Cumulatively $95.5 \%$ had a positive experience in the facility environment while $4.5 \%$ (see Table 11).

"We are forced to share beds together with our newborns which can expose us to infections such as Corona and the toilets are sometimes dirty," said an FGD participant.

Table 10: Facility Environment

\begin{tabular}{llll}
\hline Statement & Yes & No & Total \\
\hline \multirow{2}{*}{ Was there enough health staff in the facility to care for you? } & 324 & 36 & 360 \\
& $90 \%$ & $10 \%$ & $100 \%$ \\
\hline Considering the labour and postnatal wards, do you feel the health facility & was 195 & 165 & 360 \\
crowded? & $54 \%$ & $46 \%$ & $100 \%$ \\
\multirow{2}{*}{ Was water available in the facility? } & 358 & 2 & 360 \\
& $99 \%$ & $1 \%$ & $100 \%$ \\
\hline \multirow{2}{*}{ Was electricity available in the facility? } & 360 & 0 & 360 \\
In overall, can you say that you felt safe in the health facility? & $100 \%$ & $0 \%$ & $100 \%$ \\
\hline
\end{tabular}

Table 11: Cumulative Experience in the Facility environment

\begin{tabular}{llll}
\hline Category & Frequency & Per cent & Cumulative Percent \\
\hline Highly & 343 & 95.5 & 95.5 \\
Moderate & 17 & 4.5 & 100.0 \\
Low & 8 & 1.9 & 100.0 \\
Total & $\mathbf{3 6 0}$ & $\mathbf{1 0 0 . 0}$ & \\
\hline
\end{tabular}

10 This work is licensed under a Creative Commons Attribution 4.0 International License. 


\section{Overall Rating by the Respondents}

The majority of the respondents $(62.8 \%)$ were satisfied with the services offered at the facility, followed by $19.4 \%$ who were very satisfied. $15.3 \%$ were neither satisfied nor dissatisfied, $1.9 \%$ were dissatisfied, while $0.3 \%$ were very dissatisfied (see Table 12). $40.8 \%$ of the respondents rated the level of quality of care as good, $37.7 \%$ rated the quality of care as fair, $16.4 \%$ rated the quality of care as very good, while $3.1 \%$ rated the quality of care as excellent (Table 13). 68.9\% said they would definitely deliver in the same facility again, $28.1 \%$ said that they would somewhat deliver in the same facility again, while 3\% said that they would not deliver in the same facility again (Table 14). 69.8\% said that they would definitely recommend another woman to deliver in the facility, $24.4 \%$ said that they would somewhat recommend another woman to deliver in the facility, while $5.8 \%$ said that they would not recommend another woman to deliver in the facility (Table 15).

Table 12: Rating of the Level of satisfaction with the services offered at the facility

\begin{tabular}{llll}
\hline Category & Frequency & Per cent & Cumulative Percent \\
\hline Neither satisfied nor dissatisfied & 55 & 15.3 & 15.3 \\
Satisfied & 226 & 62.8 & 78.1 \\
Very Satisfied & 70 & 19.4 & 97.5 \\
Dissatisfied & 7 & 1.9 & 99.4 \\
Very Dissatisfied & 2 & .6 & 100.0 \\
Total & $\mathbf{3 6 0}$ & $\mathbf{1 0 0 . 0}$ & \\
\hline
\end{tabular}

Table 13: Rating on the level/quality of care offered at the facility

\begin{tabular}{llll}
\hline Category & Frequency & Per cent & Cumulative Percent \\
\hline Fair & 143 & 39.7 & 39.7 \\
Good & 147 & 40.8 & 80.6 \\
Very good & 59 & 16.4 & 96.9 \\
Excellent & 11 & 3.1 & 100.0 \\
Total & $\mathbf{3 6 0}$ & $\mathbf{1 0 0 . 0}$ & \\
\hline
\end{tabular}

Table 14: Choice to Deliver in the same facility again

\begin{tabular}{llll}
\hline Category & Frequency & Per cent & Cumulative Percent \\
\hline Yes, somewhat & 101 & 28.1 & 28.1 \\
Yes, definitely & 248 & 68.9 & 96.9 \\
No & 11 & 3.0 & 100.0 \\
Total & $\mathbf{3 6 0}$ & $\mathbf{1 0 0 . 0}$ & \\
\hline
\end{tabular}

Table 15: Recommendation to another Woman to Deliver in the Facility

\begin{tabular}{llll}
\hline Category & Frequency & Per cent & Cumulative Percent \\
\hline Yes, somewhat & 88 & 24.4 & 24.4 \\
Yes, definitely & 251 & 69.7 & 94.2 \\
No & 21 & 5.8 & 100.0 \\
Total & $\mathbf{3 6 0}$ & $\mathbf{1 0 0 . 0}$ & \\
\hline
\end{tabular}

\section{Prevalence of Disrespect and Abuse}

$57.8 \%$ rated the user experience of care highly, $36.6 \%$ rated it moderately, while $5.6 \%$ rated low the positive user experience of care. The prevalence of experiencing any form of disrespect and abuse at baseline was at $42.2 \%$ (Table 16).

11 | This work is licensed under a Creative Commons Attribution 4.0 International License. 
Table 16: Prevalence of Disrespect and Abuse at Baseline

\begin{tabular}{|c|c|c|c|c|c|c|}
\hline & \multirow{3}{*}{$\begin{array}{l}\text { Dignity } \\
\text { and } \\
\text { Respec }\end{array}$} & \multirow{3}{*}{$\begin{array}{l}\text { Autonomy, } \\
\text { Privacy and } \\
\text { Confidentiali } \\
\text { ty }\end{array}$} & Communicatic & \multirow{3}{*}{$\begin{array}{l}\text { Supportiv } \\
\text { e Care }\end{array}$} & \multirow{3}{*}{$\begin{array}{l}\text { Facility } \\
\text { Environmen } \\
\text { t }\end{array}$} & \multirow{3}{*}{$\begin{array}{l}\text { Cumulative } \\
\text { Prevalence of D\&A } \\
(\%)- \\
\text { divided by } 5\end{array}$} \\
\hline & & & & & & \\
\hline & & & & & & \\
\hline Highly & 4.8 & 3.4 & 95.3 & 90.0 & 95.5 & 57.8 \\
\hline Moderate & 78.2 & 87.5 & 4.7 & 8.1 & 4.5 & 36.6 \\
\hline Low & 17 & 9.1 & 0 & 1.9 & 0 & 5.6 \\
\hline
\end{tabular}

\section{SUMMARY OF THE FINDINGS}

\section{Socio-Demographic Characteristics of the Study Population}

Women aged 15-19 years experienced disrespect and abuse more compared to older women who were less likely to experience disrespect abuse. This was also established in a survey in Tshwane Health District, South Africa which found out that age was significantly associated with disrespectful care with younger women being more prone (Oosthuzein et al., 2017). Married women were more likely to experience disrespect and abuse compared to women who were single or divorced/separated. This finding concurs with those of Abuya et al., 2015 which found out that married women were more likely to experience disrespect and abuse including being neglected.

Women who had a primary or lower level of education were more likely to experience disrespect and abuse compared to women with a higher level of education who were less likely to experience disrespect and abuse. This is consistent with a study carried out in Guatemala which found out that disrespectful and abusive maternity care was a common and pervasive problem among marginalised and less educated women (Austad et al., 2017).

\section{Treatment of Mothers during Childbirth (Experience of Care/Respectful Maternity Care)}

There is a poor provider-patient relationship during childbirth in the health facilities and most women experience physical abuse and discrimination (Namusonge \& Ngachra, 2021; George-Cavey, 2018). Some providers do not introduce themselves to the women (Siraj et al., 2019). The results of this study indicate that there were incidents where women experienced disrespect and abuse whereby they were talked to in an unfriendly manner and did not introduce themselves to the women, which also came out evidently from many women during FGD.

Afulani et al. (2017) recommended four factors influencing women's perceptions of quality care: responsiveness, supportive care, dignified care and effective communication. The study revealed that most women experienced responsive care; however, there were incidences whereby some women experienced care that was not responsive.

Bartlett (2015) reported incidences of terrible abuses in health facilities in the Philippines that reflected a lack of value to the lives of women and newborns. Women who reported to have experienced disrespect and abuse were less likely to plan delivery in a facility in the future (Kruk et al., 2014; Abuya et al., 2015). In support of the findings, this study has also shown that some women reported having had a poor experience whereby they received unfriendly and insensitive treatment from some of the health care providers who went to the extent of being sarcastic to the women. These women reported that they would not wish to deliver in the same facility in future. Provision and experience of care- how women are treated-are both critical components of quality that can influence service utilisation and health outcomes (WHO, 2018).

Most women receive non-confidential care whereby their information is divulged to people not involved in their care and are not covered and beds screened during examination (George-Cavey, 2018). 81.7\% of the women were not accorded privacy by use of curtains/visual barriers (Siraj et al., 2019). In agreement with the findings, this study revealed that women's privacy and confidentiality was inadequate due to a congested bed occupancy that forced them to share beds alongside their newborns and there were no screens or curtains. Contrary to 
the findings, this study found that women's information was not divulged to people not involved in their care.

In this study, it was evident that the doctors, nurses and other staff did not involve women in decision making about their care. Some women reported that permission or consent was not obtained from them by the doctors, nurses or other staff at the facility before doing procedures and examinations on them. Some women also reported that they could not voice their dissatisfactions since they felt debased by some healthcare providers and hence, they could not be listened to. Silva et al. (2015) suggested that factors considered to promote autonomy such as promotion of coercion-free personal relationships, facilitating access to information, and fostering active participation of women were negligible and hence more effort was required to fully achieve this goal. Women should participate in decisions about their care (Chalmers, 1992).

Communication in health helps in advancing the health and wellbeing of women and their newborns. Poor rapport and communication between women and providers and failure to meet professional standards in most healthcare facilities (WHO, 2015). This study revealed that despite there being good communication and supportive care from some healthcare providers, some women reported that communication was inadequate with some experiencing negative attitudes from the healthcare providers as well as not being told about the kind of medication or care they were receiving.

The presence of a birth companion enhances positive user experience as well as labour and delivery outcomes. Barriers to humanising birth care include the institutional rules and strategies that restrict the presence of a birth companion (Behruzi et al., 2010). A study in Kenya by George-Cavey (2018) found out that many facilities lacked basic equipment and infrastructure including electricity and water as well as skilled birth attendants and emergency care capacity. These findings concur with the findings of the present study whereby the health facilities lacked adequate supplies, space and beds to accommodate the patient population as well as skilled birth attendants.

This study revealed that $57.8 \%$ experienced dignity and respect. This gives us the prevalence of disrespect and abuse to be $42.2 \%$ as per the exit interview and 2 in 5 experienced feeling humiliated during labour in Bungoma County. This finding surpasses the prevalence in Kenya by George-Caey (2018) which stated that $20 \%$ of women reported having experienced some form of disrespect and abuse, and 1 in 5 experienced feeling humiliated during labour (George-Cavey, 2018).

\section{Factors Contributing to Disrespect and Abuse During Childbirth}

It was evident in this study that there was staff shortage as well as healthcare provider demotivation due to lack of promotions and inadequate support supervision from the managers which could be attributed to negative user experience. The findings are in agreement with Hasting (2015) who found out that limited resources; stressful working conditions; and institutional factors such as poor health worker supervision, substandard infrastructure, and lack of accountability as some of the factors leading to disrespect and abuse. The usefulness of the midwife has conventionally been associated with maintaining standards of care hence the need for ensuring adequate deployment to avoid human resource shortage (Abott et al., 2010).

WHO, 2015 stated that poor rapport between women and providers as well as lack of cooperation and trust towards healthcare providers led to disrespect and abuse.This current study disclosed that poor understanding and negative attitudes between the healthcare providers and mothers led to disrespect and abuse. The findings were also confirmed by most of the midwives in an in-depth interview.

In FGD, most women disclosed that they laboured at home for more than 12 hours before deciding to go to the health facility. The majority of them ended up being done caesarean section due to complications. Their lack of seeking prompt healthcare was attributed to fear of receiving inadequate treatment, lack of reliable transport and low compliance to referral advice. The findings compare well with those carried out in the Philippines that found out that disrespect and abuse contributed to delays \#1 and \#3 (Bartlett, 2015). Lack of reliable transport, costs involved and

13 This work is licensed under a Creative Commons Attribution 4.0 International License. 
perceived quality of care at the hospitals led to delays in seeking healthcare (Pembe et al., 2008). If a woman does not feel safe and respected when she first visits a maternity centre, she is less likely to seek delivery services in good time hence increasing her risk of both pregnancy-related morbidity and mortality.

Too much workload made healthcare providers take the shortest time possible per client to serve all of them hence leading to substandard care that may be equated to disrespect and abuse, as revealed by most midwives in the in-depth interview. This finding corresponds with that of the Kenya National Commission on Human Rights which found out that Kenya's public health facilities have long been plagued by reports of abuse, mistreatment, and negligence of patients in the hands of staff which could be attributed to poor supervision and understaffing (Bourbonnais, 2013).

The study showed as recounted by many of the midwives in in-depth interviews, that some cultural factors such as the use of traditional herbs by some women during labour while in the hospital made them be treated with disrespect and abuse since cultural practices were not allowed in the hospital. The finding corresponds with those of Afolabi et al. (2009) who found out that culturally inappropriate care, disrespectful and inhuman services and lack of emotional support can deter women from accessing obstetric care. There is a need for healthcare providers to be respectful of women's cultural beliefs and practices as long as they are not detrimental.

Mistreatment can occur at the level of interaction between the woman and provider, as well as through systemic failures at the health facility and health system levels (Bohren et al., 2015). Drivers to disrespect and abuse can be at the policy, facility, and community levels (Ndwiga, 2017). In agreement, this study found out that communication barrier between the women and provider or not giving adequate information, shortage of healthcare providers, inadequate training and support supervision, and women sharing beds alongside their newborns, which curtailed their privacy and exposed them to nosocomial infections were some of the factors leading to disrespect and abuse. Mirkuzie et al. (2014) reported that lack of national commitment and financial support; poor decisionmaking power among women; absence of access to, availability and quality care during pregnancy and delivery; poorly functioning health systems with weak referral systems, especially during obstetric and neonatal emergencies; and weak national human resource development and management, comprising the continuing brain drain of skilled personnel. These findings correspond with those of this study in that some women laboured at home for more than 24 hours before reaching the hospital due to fear of the healthcare care providers and undergoing caesarean section of which ended being done due to obstetric complications that could have come up due to delays. There was a shortage of staff due to transfers and resignations. On the contrary, the current study found out that transport was not a barrier to accessing a health facility in Bungoma County, as suggested by Gabrysch et al. (2009).

\section{Strategies for Addressing Issues Affecting Respectful Maternity Care for Promoting Quality of Maternal and Newborn Care}

To ensure women understand their rights, duties and responsibilities, targeted information, education and communication should be provided (Hailu \& Mariam, 2013). The recommendations concur with the findings of this study as suggested by most of the key informants in the in-depth interview who said that adequate education should be provided to women during ANC visits so as to allay myths and misconceptions and also seek medical care in good time so as to avoid obstetric complications.

Most of the key informants in in-depth interviews suggested that leadership and supervision by the CHMTs, SCHMTs and health managers ought to be scaled up for purposes of accountability and quality checks. This recommendation agrees with that of the World Health Organization that says that strengthening monitoring and evaluation can go a long way in improving maternal and newborn health outcomes.

When providing care to women, obstetric nurses should develop actions geared towards individualised, welcoming and efficient care in an environment enabling integral care practices (Silva et al., 2015). This was also suggested in this study by most of the key informants who stated that 
healthcare providers should be welcoming, adhere to privacy and confidentiality, listen to clients' needs and concerns; empathetic and involve women in decision making.

Most of the key informants in this study suggested that all structures, i.e., community, health facilities, CHMT/SCHMT, the national level, GOK structures, professional associations, should provide peer review in ensuring that all the healthcare professionals are held to account. Legal address mechanisms should be provided to ensure that victims of disrespect and abuse get justice. The findings were also suggested by Ndwiga (2017) who said that respectful maternity care requires that all levels of healthcare work concurrently because no single effort or intervention can on its own reduce disrespect and abuse.

It was proposed by most of the key informants in this study that in order to curb disrespect and abuse, the following should be done by the health facilities: exit interviews for mothers, suggestion boxes for compliments and complaints, availing hospital phone numbers to the public and installing CCTV cameras. This is supported by WHO, 2013 who suggested that strengthening monitoring and evaluation can go a long way in improving maternal and newborn health outcomes.

Autonomy during childbirth includes the promotion of coercion-free personal relationships, facilitating access to information and fostering the active participation of women (Silva et al., 2015). The findings correlate with those of this study which additionally suggested that women should also be given adequate education during ANC visits so as to allay myths and misconceptions, ensure they seek medical care in good time and not labouring at home for too long only to go to the hospital when they experience complications.

Quality of care means ensuring that women's voices and opinions are prioritised when developing interventions to improve quality in maternity care provision. The results were richest across the domains of effective communication, respect and dignity, emotional support, competent and motivated human resources, and essential physical resources (Bohren et al., 2017). Similarly, this study findings recommended employment of more human resources for health, continuous quality standard checks by healthcare managers, sensitisation of healthcare providers on respective maternity care that may help allay negative attitudes, autonomy, dignity and respect.

\section{CONCLUSION}

On the assessment of the socio-demographic characteristics, it was found that younger women were more likely to experience disrespect and abuse compared to older women. Married women were more likely to experience disrespect and abuse. Women who had primary or less level of education were more likely to experience disrespect and abuse

Overall the study found out that the majority of the women experienced dignity and respect from the doctors, nurses and other healthcare providers. The majority of the healthcare providers were responsive to the women's needs offered supportive and dignified care as well as effective communication. Despite the positive user experience by most of the respondents, some women reported having had a poor experience that was unfriendly and insensitive. Women who experienced poor treatment reported not to deliver in the facility in future or recommend another woman to deliver in the facility. Inadequate privacy and confidentiality, autonomy in decision making and not allowing the presence of a birth companion during labour and delivery were found to be major aspects of disrespect and abuse. The prevalence of disrespect and abuse was $42.2 \%$.

It was found out that the major factor leading to disrespect and abuse or negative user experience was staff shortage as well as healthcare providers demotivation due to lack of promotions and inadequate support supervision from managers. Poor understanding and negative attitudes between healthcare providers and women led to disrespect and abuse. Communication barrier or not giving adequate information to the clients cause incorporation which eventually led to disrespect and abuse. Women labouring at home for more than 12 hours then coming to the hospital with obstetric emergencies aggravated disrespect and abuse. Lack of adequate medical equipment and supplies, health staff, small rooms and lean bed capacity to accommodate the patient population and not allowing the presence of family members 
contributed to disrespect and abuse. Not honouring women's cultural practices also led to disrespect and abuse.

Strategies identified in addressing issues affecting respectful maternity care in promoting quality of maternal and newborn care included the provision of adequate education to mothers during ANC visits so as to ally myths and misconceptions and also seek medical care in good time so as to avoid obstetric complications. Another strategy was for the health managers to scale up supervision for purposes of accountability and quality checks and that they should not be harsh and problem searching. Healthcare providers should be welcoming, adhere to privacy and confidentiality and listen to clients' needs and concerns. Adhering to code of regulations by staff/healthcare providers. Another strategy was staff motivation through promotion and provision of adequate resources. Respect of positive cultural practices and incorporating respectful maternity care practices in the routine quality checks.

Provision of respectful maternity care during childbirth is a women's right and any form of disrespectful and abusive treatment not only violates the rights of women to respectful care but also threatens their rights to life, health, bodily integrity and freedom from discrimination.

\section{Recommendations}

The Ministry of Health should develop a policy guideline on Respectful Maternity Care and include RMC into routine care and there should be continuous sensitisation as well as monitoring and evaluation so as to ensure positive impact. Research and implementation efforts must continue to ensure that all new mothers receive the dignified positive birth experience they deserve no matter the circumstances.

The Ministry of Health should ensure adequate deployment of human resources for health who are motivated. Equipment and supplies should be made adequate as well as adequate space and bed capacity that can accommodate the patient population. The ministry of culture, gender and social services should address socio-cultural factors that lead to disrespect and abuse including women empowerment and delay in seeking medical care in good time.

Mixed methods study designs should be used as the optimal strategy to evaluate mistreatment. The inclusion of direct observations may help bridge the gap between observed measures and participants' self-reported experiences of mistreatment. Evaluation efforts need to reflect the fact that meaningful change will tend to be long-term and that treatment of mothers during childbirth activities will occur over a long period of time and thus evaluation will also take place over time.

\section{ACKNOWLEDGEMENT}

I sincerely appreciate God for seeing us through the entire study. I would like to extend my appreciation to everyone who made this study feasible and the achievement of my ideas and objectives a reality.

First and foremost, to my supervisors Dr. Maximilla Wanzala and Prof. Edwin K. Wamukoya for their constant support, patience, mentorship, helpful corrections and suggestions throughout this thesis development. I can never thank you enough. A lot of appreciation goes to Dr. Nathan Shaviya and my colleagues for their generous advice and corrections.

Secondly my research assistants, Mr. Amos Yator, Mr. Brian Sitonik, Ms. Evonne Naliaka Wafula and Ms. Carolyne Mukoya who worked tirelessly to ensure quality data collection and Mr. Omukoba Mulati, Mr. Julius Kamau Mwangi, Mr. Blasio Omulama Amoche for their expertise in data analysis using SPSS v.25.0. To the management of Bungoma County Referral Hospital and Webuye County Hospital, and the nurses in maternity units in the respective health facilities. Thank you for welcoming me with open hands.

To the women of Bungoma County who sacrificed their valuable time in order to participate in the research through responding to the exit interviews and focus group discussions and for sharing their most intimate moments with such enthusiasm. Finally, to the School of Public Health and Biomedical Sciences of Masinde Muliro University of Science and Technology for their tireless efforts and guidance towards ensuring completion of this study.

16 This work is licensed under a Creative Commons Attribution 4.0 International License. 
Thanks also to all other people who contributed in one way or the other.

\section{REFERENCES}

Abbott, P., Burgess, K., Wang, E., \& Kim, K. (2010). Analysis of dentists' participation in continuing professional development courses from 2001-2006. The open dentistry journal, 4, 179.

Abuya, T., Ndwiga, C., Ritter, J., Kanya, L., Bellows, B., Binkin, N., \& Warren, C. E. (2015). The effect of a multi-component intervention on disrespect and abuse during childbirth in Kenya. BMC pregnancy and childbirth, 15(1), $1-14$.

Afolabi, B. B., Iwuala, N. C., Iwuala, I. C., \& Ogedengbe, O. K. (2009). Morbidity and mortality in sickle cell pregnancies in Lagos, Nigeria: a case control study. Journal of Obstetrics and Gynaecology, 29(2), 104-106.

Afulani, P. A., Kirumbi, L., \& Lyndon, A. (2017). What makes or mars the facility-based childbirth experience: thematic analysis of women's childbirth experiences in western Kenya. Reproductive health, 14(1), 1-13.

Austad, K., Chary, A., Martinez, B., Juarez, M., Martin, Y. J., Ixen, E. C., \& Rohloff, P. (2017). Obstetric care navigation: a new approach to promote respectful maternity care and overcome barriers to safe motherhood. Reproductive health, 14(1), 1-8.

Bartlett, R. (2015). Respectful Maternity Care is everyone's responsibility. IntraHealth Internatio nal.

Behruzi, R., Hatem, M., Fraser, W., Goulet, L., Ii, M., \& Misago, C. (2010). Facilitators and barriers in the humanisation of childbirth practice in Japan. BMC pregnancy and childbirth, 10(1), 1-18.

Bohren, M. A., Hunter, E. C., Munthe-Kaas, H. M., Souza, J. P., Vogel, J. P., \& Gülmezoglu, A. M. (2014). Facilitators and barriers to facility-based delivery in low-and middle-income countries: a qualitative evidence synthesis. Reproductive health, 11(1), 1-17.

Bohren, M. A., Titiloye, M. A., Kyaddondo, D., Hunter, E. C., Oladapo, O. T., Tunçalp, Ö., ... \& Mugerwa, K. (2017). Defining quality of care during childbirth from the perspectives of Nigerian and Ugandan women: A qualitative study. International Journal of Gynecology \& Obstetrics, 139, 4-16.

Bohren, M. A., Vogel, J. P., Hunter, E. C., Lutsiv, O., Makh, S. K., Souza, J. P., ... \& Gülmezoglu, A. M. (2015). The mistreatment of women during childbirth in health facilities globally: a mixed-methods systematic review. PLoS medicine, 12(6), e1001847.

Bourbonnais, N. (2013). Implementing free maternal health care in Kenya: challenges, strategies, and recommendations (No. BOOK). The Kenya National Commission on Human Rights.

Chalmers, B. (1992). WHO appropriate technology for birth revisited. British journal of obstetrics and gynaecology, 99(9), 709-710.

Furuta, M., Sandall, J., \& Bick, D. (2014). Women's perceptions and experiences of severe maternal morbidity-A synthesis of qualitative studies using a meta- ethnographic approach. Midwifer $y, 30(2), 158-169$.

Gabrysch, S., Civitelli, G., Edmond, K. M., Mathai, M., Ali, M., Bhutta, Z. A., \& Campbell, O. M. (2012). New signal functions to measure the ability of health facilities to provide routine and emergency newborn care. PLoS medicine, 9(11), e1001340.

Gary P.R. (2007). Adjusting for Non-response in Surveys. In: Smart J.C. (eds) Higher Education: Handbook of Theory and Research, Springer, Dordrecht.

George-Cavey, R. (2018, April 12). Landmark Ruling in Kenya: A Victory for Respectful Maternity Care. Maternal Health Task Force. https://www.mhtf.org/2018/04/12/landmarkruling-in-kenya-a-victory-for-respectfulmaternity-care/ 
Hailu, A., \& Mariam, D. H. (2013). Patient side cost and its predictors for cervical cancer in Ethiopia: a cross sectional hospital-based study. $B M C$ cancer, 13(1), 1-8.

Hastings, M. B. (2015). Pulling back the curtain on disrespect and abuse: the movement to ensure respectful maternity care. Washington, DC: White Ribbon Alliance.

Kothari, C. R. (2004). Research methodology: Methods and techniques. New Age International.

Kruk, M. E., Kujawski, S., Mbaruku, G., Ramsey, K., Moyo, W., \& Freedman, L. P. (2018). Disrespectful and abusive treatment during facility delivery in Tanzania: a facility and community survey. Health policy and planning, 33(1), e26-e33.

Mirkuzie, A. H., Sisay, M. M., Reta, A. T., \& Bedane, M. M. (2014). Current evidence on basic emergency obstetric and newborn care services in Addis Ababa, Ethiopia; a cross sectional study. BMC pregnancy and childbirth, 14(1), 1-8.

Namusonge, L. N., \& Ngachra, J. O. (2021). Respectful Maternity Care Interventions: A Systematic Literature Review. East African Journal of Health and Science, 3(1), 45-58.

Ndwiga, C. (2017). Advancing respectful maternity care in Kenya: a comprehensive approach. Population Council. https://www.popcouncil.or g/news/advancing-respectful-maternity-care-inkenya-a-comprehensive-approach

Oosthuizen, S. J., Bergh, A. M., Pattinson, R. C., \& Grimbeek, J. (2017). It does matter where you come from: mothers' experiences of childbirth in midwife obstetric units, Tshwane, South Africa. Reproductive health, 14(1), 1-11.

Oppenheim, A.M. (2009). Questionnaire design, Interviewing and Attitude Measurement. New edition. Printer Publications. New York.

Pembe, A. B., Urassa, D. P., Darj, E., Carlstedt, A., \& Olsson, P. (2008). Qualitative study on maternal referrals in rural Tanzania: decision making and acceptance of referral advice. African journal of reproductive health, 12(2), 120-131.

Silva, A. L. S., Nascimento, E. R. D., \& Coelho, E. D. A. C. (2015). Nurses practices to promote dignity, participation and empowerment of women in natural childbirth. Escola Anna Nery, 19, 424-431.

Siraj, A., Teka, W., \& Hebo, H. (2019). Prevalence of disrespect and abuse during facility based child birth and associated factors, Jimma University Medical Center, Southwest Ethiopia. BMC pregnancy and childbirth, 19(1), 1-9.

Wiegers, T. A. (2009). The quality of maternity care services as experienced by women in the Netherlands. BMC pregnancy and childbirth, 9(1), 1-11.

World Health Organization (WHO). (2018). WHO recommendation on respectful maternity care during labour and childbirth. Global Health Project. World Health Organization

World Health Organization. (2010). Quality of care; Patient safety. Report by the Secretariat. Fiftyfifth World Health Assembly, provisional agenda item 13.9. 2010.

World Health Organization. (2014a). Every Newborn: an action plan to end preventable deaths. World Health Organization

World Health Organization. (2014b). MDG 5: Improve Maternal Health. WHO Mediacentre Factsheet. World Health Organization

World Health Organization. (2015). WHO statement on prevention and elimination of disrespect and abuse during childbirth. Global Health Project. World Health Organization

18 This work is licensed under a Creative Commons Attribution 4.0 International License. 